\title{
Rhythms of the Domestic Soundscape: Ethnomethodological Soundwalks for Phatic Technology Design
}

\author{
Hanif Baharin ${ }^{1}$, Sean Rintel ${ }^{2}$, and Stephen Viller ${ }^{2}$ \\ ${ }^{1}$ Universiti Teknologi MARA Malaysia, 40450 Shah Alam, Selangor, Malaysia \\ ${ }^{2}$ The University of Queensland, Brisbane, QLD, 4072 Australia \\ ahmadhanif@perlis.uitm.edu.my, \\ s.rintel@uq.edu.au, viller@acm.org
}

\begin{abstract}
The importance of the domestic soundscape as a context for technological interventions has received little attention in HCI research. In this paper, we discuss how an ethnomethodological soundwalk method facilitated design principles for a phatic technology probe for seniors living alone. Taking soundscape concepts as a starting point, we suggest that the soundwalk works much like a breaching experiment, changing the participant's role in engaging with their soundscape from reactive automatic agent to proactive reflective agent. This enables participants to reveal their own systematic orderliness when accounting for everyday sounds. We find that sounds are accounted for in terms of people placed in narratives. As such, we argue that phatic technologies use new sounds and rhythms to augment the domestic soundscape to take advantage of people's abilities to create social narratives from limited cues.
\end{abstract}

Keywords: Domestic soundscape, soundscape study, ethnomethodology, breaching experiment.

\section{Introduction: Phatic Audio Technologies}

The importance of the domestic soundscape as a context for technological interventions has received little attention in human-computer interaction (HCI) research. In Australia, about 29 percent of people who are 65 years of age and over and 39 percent of people aged 85 years and over lived alone in 2006 [1]. Inspired by Tacchi's work [2] showing that the radio is used in domestic settings to negate the feeling of social isolation, we are exploring new design ideas for phatic audio technologies: lean audio signalling "awareness systems [that] contribute to a feeling of human connectedness" [3:178] through interventions into the domestic "soundscape" [4] that encourage social narratives. In this paper, we discuss an ethnomethodological [4, 5] version of Schafer's [6] soundwalk method in which we found that even when living alone, the domestic soundscape is adorned by the sounds of other people which are accounted for in terms of social narratives. The design implication of this finding is that lean signalling can be leveraged to encourage such social narratives for a range of use cases. 


\subsection{Soundscape Approach in HCI}

As opposed to visual displays, HCI design research on soundscape augmentation has been quite limited. This research, however, consistently finds that sounds are treated as accountable and narratable. Alexanderson and Tollmar [7:255] have explored a participatory design-oriented phenomenological approach to augmenting factory soundscapes, and found that "an important part of the design process is the operator's contribution to the concepts suggested." Oleksik, Frohlich, Brown and Sellen [8], adopted the soundscape approach to inform design in the domestic context. After conducting a "sound tour", in which participants showed researchers around their homes and discussed the sounds they heard, they found that sounds in the home had special meanings and functions for the inhabitants.

In The Tuning of the World, Schafer [6] provides a novel view of the problem of noise in society. Instead of providing ways in which noise may be abated, he argues that society as a whole should be actively designing sounds in the world to make it a sonically beautiful place. Schafer [6] argues that technology has created problematic changes to the ways humans appreciate sounds in their environment, coining the term "schizophonia" to propose the tendency of people to become distracted listeners due to the technological separation of sounds from sources. Although our research adopts Schafer's approach to encourage listening, we disagree with Schafer's entirely negative evaluation of technology. We take the stance that technology can help to create a more acoustically pleasing world in which listeners are encouraged to add context to dislocated sounds.

\section{Ethnomethodologically-Informed Domestic Soundscape Study}

We see our work as a continuation of that of Oleksik et al. [8], but with an ethnomethodological stance shaping our approach and interpretation of data. We were trying to elicit how people account for their experience of the domestic soundscape and how people achieved the common sense understanding of their soundscape. Garfinkel [4] argues that social order is not governed by theories unknown to social actors, but achieved by moment-by-moment effort taken by people to organise their behaviour. Ethnomethodological investigations aim to illustrate how people make sense of the rationalisation of actions by, and as displayed by, others - in other words "What everyone knows that everyone knows" [4:75].

Schafer [6] introduces the "soundwalk", in which participants take the researcher around their house and described the sounds they hear, as a listening exercise to increase people's awareness of their soundscape. For us, the soundwalk is a way to gather the foundational data about how people make sense of the types and rhythms of sounds in their domestic environments. Rather than simply moving from room to room and passively listening, in a soundwalk the researcher guides the participants' attention to the sounds in their environment by encouraging discussion of routines 
undertaken in each area of the environment. Eight participants (three males and five females) with ages ranging from 51 to 87 were involved in this study. The names of the participants have been changed to protect their privacy. All the participants were living alone in their own homes in suburban areas in Brisbane, Australia.

Our soundwalks included both researcher-guided and self-guided versions. In the researcher-guided versions, participants were given a sound recorder and a diary (for another parallel study) and were asked to record sounds they heard in and around their dwellings. The soundwalk was conducted either when the researcher first met the participants in their home or when the researcher visited them a week later to collect the diary and the sound recorder. Data from the soundwalk and diary were analysed to inform interview guides. During interviews, they were encouraged to reflect on the recording process and the sounds they recorded. For privacy reasons some participants conducted self-guided soundwalks. They were given an information pack containing a diary, a sound recorder, and stationery. They were instructed to draw a plan of their home, and go through every room and area, listing the sounds they heard based on their daily routine, and to take the sound recorder along with them to record the sounds they heard.

\section{Soundscape Narratives and Rhythms}

\subsection{The Mundane Soundscape}

For the participants there was nothing profound about the everyday sounds they heard, from within and outside the home, because the sounds were a part of 'normal life' (e.g. Janet). However, many of these participants expressed mundanity through evaluative paradigms: being alive or not (e.g. Janet) or whether sounds might be a cause for 'worry' or not (e.g. Ian). The evaluative nature of even baseline 'nothing special' responses is, we argue, a fundamental feature of the accountability of the soundscape.

Janet: Well you do know that life is normal. You're alive. Perhaps you could tell but you could be walking around like zombie not alive but if you don't hear the sound and the noises of everyday activity. You know you're conscious [laugh].

Ian: So, I do hear noises, but they don't worry me. Some of them might mean something. Some of them don't.

\subsection{Sounds Mean People in Narratives}

Our analysis of the participants' diaries and of the first few interviews revealed that all participants described other people as the producers of sounds in their soundscape. Despite living alone, other people's sounds were treated as decorating their soundscape. 
Lucy: Eh but there is sound going all the time, I mean there are people coming and going, and that cat, I mean the door is not always open but you can...

Marge: Well, you feel like little people about, you know? Because he goes to work all day, this one's not there. And you don't sort of see these people in the complex very much, so you've got the sound of the children, which is quite nice.

These sounds about other people in domestic soundscapes are also talked about in the form of narratives. For example, Janet wrote in her diary:

Janet (Diary): Noisy street, people coming back from stadium to collect their cars.

When Janet wrote this, she was not describing what she heard as discrete sound stimuli in their objective forms, such as footsteps on asphalt or engines being ignited. Rather, she formulated the sounds in terms of other people undertaking social activities with narrative elements - places, characters, and events - and narrative structures - time and reasoning. We found many instances where the participants talked about their domestic soundscape in terms of other people's actions. As shown in bold in the transcripts below, a similar structural pattern of expression was found in the responses of many participants: The sound event was first presented in its narrativised form, and then reformulated in terms of the discrete objective sound stimulus:

Roseanne: Right, the only other sound I hear from this area, and when the windows are open I might hear my neighbours showering. Or I hear the shower.

Karl: Yes actually the people at the back have some teenage boys and sometimes they'd kick a football around and you hear the sound of football being kicked and you know that's my neighbour at the back. The kids are playing.

Lucy: You know, I mean it - you can't help it here, I mean you can hear when other people go to the toilet because the toilet, well sometimes you can hear when the toilet flushes.

It is not within the scope of this paper to speculate why this pattern was so commonly employed. The more important point is to notice that the process of undertaking the soundwalk provided a way for participants to endogenously notice their own methodical practice of accountability, a reflexive version of what Garfinkel (after Mannheim) referred to as the "documentary method of interpretation" [4:78] .

\subsection{Soundscape Rhythm}

Similar to Oleksik et al. [8], we found participants contextualising sounds as chronological aggregates: rhythms. These rhythms were used in narratives, usually coalescing around the meaningful activities associated with a time of day. Rhythms in the 
domestic soundscape were especially focused upon the repetition of time-heralding sounds, such as radio programs, clock chimes, and church bells:

Lucy: Well I know what programs are on, I mean I listen to Radio National most of the time, and I would know usually what programs are on what time. I mean I mightn't know precisely to the minute because they rarely announce the time. But I know if it were between nine and ten, because ah, between nine and ten there's "Life Matters", after ten, there's a, whatever they call it "Book review" or something [...].

Ian: Yes, way up in the back a long way up the hill a church bell rings at five o'clock every night.

Participants also learned rhythms and developed narratives about nearby houses. Ian knew how often the house near his was occupied based on the sounds made by its occupants and Karl recognised that during the renovation of his neighbour's house the noise started at seven every morning:

Ian: No, it's just background noise, it's there, you know something's going on. There's nobody there very much during the day. Even less on that side, people come down about once a month. Stay there three days. And I can hear when they're home. Because they've got wooden floors [laughter].

Karl: The exhaust fan [of my neighbour] I would normally hear in the kitchen or in the launch room because it's about there, and the renovations mainly I would hear them here, because they start in the morning, they start about seven.

The ability to learn and draw meaning from soundscape rhythm is most clearly shown when the participants discuss variation or disruption of the learned rhythm. Janet noticed her clock was not working properly, when it did not produce the same rhythm:

Janet: You know what I mean. It gives one on the quarter, two on the half and then you got the fourth on the, you know so. As I say, I couldn't tell you whether it chimed or not because it's a noise that must happen. I only know when something's gone wrong you know.

Roseanne could discern the changes in her neighbour's routine based on the change of her soundscape rhythm. She knew that there were more sounds coming from her neighbour's house during weekends than during weekdays. When she did not hear them that weekend, she speculated that they were away.

Roseanne: Because the young people who live there are at work and look I haven't heard a sound from them the whole weekend. They may have been away. Just occasionally once every three months or something they might have friends over in three o'clock in the morning. I wish they'd go home. But it doesn't happen very often so you know you think well okay. 


\section{The Ethnomethodological Soundwalk: The Soundwalk as a Breaching Experiment}

This section highlights our contribution to HCI by suggesting that the soundwalk may be treated as a form of breaching experiment. The participants experienced the domestic soundscape as mundane immersion, using their domestic soundscape as a resource for "background expectancies as a scheme of interpretation" [4:36]. That being said, they could not readily talk about the ever-present everyday sounds in their domestic soundscape without at least some prompting. This is in accordance with the observation by Garfinkel [4] that people are able to take actions based on their "background expectancies", but are "at a loss to tell us specifically of what the expectancies consist. When we ask him about them he has little or nothing to say" [4:37].

Breaching experiments were originally introduced by Garfinkel [4:38] as "aids to a sluggish imagination" to make transparent the shared common sense understandings or accounts of everyday actions. For example, by changing the accepted role of self, from being a family member to a boarder, the shared understanding of the actions that make the role of being a family member accountable can be made clear. However, when introducing a breaching experiment in HCI, Crabtree [5] is of the opinion that the disruption element of Garfinkel's experiments is taken too literally, and is hardly necessary as a required element. Indeed, not all of Garfinkel's breaching experiments reported "bewilderment". Many showed attempts to incorporate unusual behaviour into an acceptable shared framework of understanding.

We argue that this is what happened when we asked our participants to do the soundwalk. These behaviours were unusual to them as far as their experiences in engaging with their domestic soundscape are concerned. Being involved in our study was much like being involved in a breaching experiment because the participants changed their role from being reactive automatic agents to proactive reflective agents.

Our immersion in the soundscape, and our ability to monitor everyday sounds based on selective hearing, make our responses to sounds seem automatic. Many participants talked about focusing on 'something else' other than the sounds produced by their domestic activity, for example Karl said:

Karl: I guess your main focus in on something else, like you might be focusing, I'm gonna cook my dinner now, I'm gonna do the dishes [...] Not thinking about the actual sound of the plates going in the water [...] you see, you don't notice that.

However, the recording exercise changed the participants from reactive agents to proactive agents, actively seeking sounds to record, which in turn made them more reflective about their soundscape. This, in combination with soundwalk and interview, made the participants assume the role of proactive reflective agents and enabled us to decipher their common-sense understanding of their domestic soundscapes. Karl, Lisa and Roseanne elucidated this:

Karl: So it was good exercise [the recording exercise] I quite enjoyed it. Cause the more I thought about it, I thought, "Ah...what am I gonna do?" as each day went on I thought of more and more things to. But I 
listen to something "Ahh...that's a good one." and I might come back to it. Cause some things, some of the recording I might have been the third or fourth go.

Lesley: Every day there are sounds no matter where you go.[...] I mean I realized that I can hear the noise around now until I just stopped and listened to it. But I mean you along every day activities and probably a lot of sound you completely don't realize there have been made.

Roseanne: And if you hadn't asked me to listen, I probably wouldn't have even heard the hum of the traffic, probably because; maybe to my thoughts would be focus on something else.

Therefore, we suggest that the change of roles, as encouraged in the soundwalk may be used as a breaching experiment to elicit the understanding of sounds in HCI research. Researchers may strive to design activities for the participants, or methods that change the participant's role of being a reactive automatic agent in the soundscape to some other roles, for example, as in our case, to a proactive reflective agent.

\section{$5 \quad$ Implications for Design}

Our findings show that, although the participants were living alone, their soundscape was intrinsically bound and shaped by the presence of other people in their environment. We are not claiming that this is universal, but this is at least true for all of our participants who live in urban areas, close to other people's dwellings. There are sounds in the domestic setting that denote the presence of others, and people relate these sounds in the form of narrative, and sometimes create speculative narrative based on the limited information they get from the sounds. The sounds of other people's routines add to the rhythm of the domestic soundscape, and people have the skills to discern this rhythm and notice the variations in the rhythm.

As noted in the Introduction, this design implication of the soundwalk method, and our findings in this instance, is that limited stimuli are contextualised as narratives of self and others endogenously even if not always explicitly. Further, when their attention is drawn to their soundscape, people are able to reflexively apply a documentary method of interpretation to their own developing understandings. Therefore, our contribution lies in the suggestion that soundscape studies may be designed as a form of breaching experiment. Both findings, we argue, are fundamental to the implication that lean audio signalling can be leveraged to encourage social narratives. These social narratives could be used to in a wide range of technology interventions.

We suggest that new sounds and new rhythms may be designed to augment the domestic soundscape to take advantage of these skills. Since domestic soundscape rhythm is linked to the presence and routines of people in the environment, social narrative creation via rhythmic sounds may be encouraged by design. That being said, it also opens up design questions regarding sonic privacy and etiquette in a shared soundscape created by technology. In our own research, we have used these ideas to 
create a phatic telecare technology probe called SonicAir, which uses lean audio signalling to represent the actions of a remote friend or family member. When SonicAir connected the homes of two people living alone, they were able to develop an ambient sense of social connection from which both took comfort. We believe that representing a remote person using audio phatic technology could be applied alongside telecare monitoring technologies to provide some of the benefits of social relationships while allowing for continued independence.

Acknowledgements. We are grateful to the participants for their time throughout our soundscape study and associated research.

\section{References}

1. Australian Institute of Health and Welfare: Older Australia at a glance (fourth edition). Cat. no. AGE 52, AIHW, Canberra, Australia (2007), http: / / www .aihw.gov.au/publication-detail / ?id=6442468045 (viewed May 17, 2013)

2. Tacchi, J.: Radio Texture: Between Self and Others. In: Askew, K., Wilk, R.R. (eds.) The Anthropology of Media, pp. 241-257. Blackwell Publishers Inc., Oxford (2002)

3. Vetere, F., Smith, J., Gibbs, M.: Phatic Interactions: Being Aware and Feeling Connected. In: Markopoulos, P., De Ruyter, B., Mackay, W. (eds.) Awareness Systems: Advances in Theory, Methodology and Design, pp. 173-186. Springer, London (2009)

4. Garfinkel, H.: Studies in ethnomethodology. Prentice-Hall, Englewood Cliffs (1967)

5. Crabtree, A.: Design in the absence of practice: breaching experiments. In: Proceedings of the 5th Conference on Designing Interactive Systems: Processes, Practices, Methods, and Techniques (DIS 2004), pp. 59-68. ACM, New York (2004)

6. Schafer, R.M.: The Tuning of The World. Knopf, New York (1977)

7. Alexanderson, P., Tollmar, K.: Being and mixing: designing interactive soundscapes. In: Proceedings of the 4th Nordic Conference on Human-computer Interaction: Changing Roles (NordiCHI 2006), pp. 252-261. ACM, New York (2006)

8. Oleksik, G., Frohlich, D., Brown, L.M., Sellen, A.: Sonic interventions: understanding and extending the domestic soundscape. In: Proceedings of the SIGCHI Conference on Human Factors in Computing Systems (CHI 2008), pp. 1419-1428. ACM, New York (2008) 